\title{
EXECUÇÃO DE SOLEIRAS VEGETADAS PARA CORREÇÃO DAS CONDIÇÕES HIDRÁULICAS DE UM CANAL DE DRENAGEM: ESTUDO DE CASO
}

\footnotetext{
Junior Joel Dewes ${ }^{1}$; Rita dos Santos Sousa ${ }^{2}$; Fabrício Jaques Sutili ${ }^{3}$

${ }^{1}$ Mestrando do Programa de Pós-graduação em Engenharia Florestal, Universidade Federal de Santa Maria, Santa Maria, Brasil. Email: juniordewes2011@gmail.com ${ }^{2}$ Doutoranda do Programa de Pós-graduação em Engenharia Florestal, Universidade Federal de Santa Maria, Santa Maria, Brasil.

${ }^{3}$ Professor doutor do Departamento de Ciências Florestais, Universidade Federal de Santa Maria, Santa Maria, Brasil.

Recebido em: 06/04/2018 - Aprovado em: 10/06/2018 - Publicado em: 20/06/2018 DOI: 10.18677/EnciBio 2018A49
}

\begin{abstract}
RESUMO
O correto dimensionamento e execução de sistemas de drenagem para sistematização de águas pluviais são essenciais para controlar o potencial erosivo do fluxo, mitigando a erosão superficial, perda de solo e/ou cobertura vegetal. Em áreas menos urbanizadas, podem ser utilizadas técnicas alternativas, menos complexas que as soluções convencionais do ponto de vista construtivo e de menor impacto ambiental, que se traduzem em ganhos econômicos e ecológicos. O objetivo deste estudo de caso foi o de implementar uma estrutura física constituída por soleiras em pedra combinadas com plantas para correção das condições hidráulicas de um canal de drenagem. $O$ relato faz uma breve caracterização do projeto e se estende até os resultados obtidos dois anos após a execução. A área de intervenção foi avaliada qualitativamente em relação ao desenvolvimento das plantas e estabilidade da obra. Foram realizadas três avaliações a campo: no momento da execução, 12 meses e 24 meses após a execução da obra. Os resultados obtidos com este trabalho confirmam que a intervenção foi eficiente na melhoria das condições hidráulicas do local, especificamente na diminuição da velocidade da água e na deposição de sedimentos no fundo do leito e nas margens e no controle dos processos erosivos atuantes. Além disso, a estrutura proporcionou condições hidráulicas e ecológicas favoráveis ao desenvolvimento vegetativo das espécies vegetais implantadas e a entrada espontânea de novas espécies no local.
\end{abstract}

PALAVRAS-CHAVE: Engenharia natural; Rugosidade hidráulica; Sistemas de drenagem.

\section{EXECUTION OF GROUNDSILLS COMBINED WITH PLANTS TO CORRECT THE HYDRAULIC CONDITIONS OF A RAINWATER DRAINAGE CHANNEL: A CASE STUDY}

\begin{abstract}
The correct design and execution of drainage systems for rainwater systematization are essential to control water erosion potential, mitigating surface erosion, soil loss and/or plant cover. In less urbanized areas, can be used alternative techniques, less
\end{abstract}


complex than conventional solutions from a constructive point of view and with lower environmental impact, which translates into economic and ecological gains. The aim of this work is to present a case study concerning the implementation of a physical structure consisting of stone groundsills combined with plants to correct the hydraulic conditions of a drainage channel, from a brief design description to the results obtained two years after its execution. The area of intervention was qualitatively evaluated in relation to the development of plants and stability of the work. Three evaluations were carried out in the field: at the time of execution, 12 months and 24 months after the execution of the work. The results obtained with this work confirm that the intervention was efficient in improving the hydraulic conditions of the site, specifically in the reduction of water velocity, deposition of sediments in the bottom of the bed and banks and in the control of active erosion processes. In addition, the structure provided favorable hydraulic and ecological conditions to the vegetative development of plants and the spontaneous colonization by new species on site.

KEYWORDS: Soil bioengineering; Hydraulic roughness; Drainage systems.

\section{INTRODUÇÃO}

A denudação é um processo natural que consiste na remoção e transporte do material da crosta terrestre, que engloba as diversas formas de erosão superficial e os movimentos de massa (DURLO; SUTILI, 2014). A remoção de material por ação do fluxo de água ocorre por erosão química e erosão física. No caso específico da erosão física a remoção do material é controlada pela erodibilidade do mesmo e pela erosividade do fluxo, ou seja, pelas propriedades físicas do material e pela competência de um fluxo produzir erosão, respectivamente (STEVAUX; LATRUBESSE, 2017).

O correto dimensionamento e execução de sistemas de drenagem para sistematização de águas pluviais são essenciais para controlar o potencial erosivo do fluxo. Estes sistemas são cada vez mais importantes devido à intensa ocupação de áreas por urbanizações e obras de infraestrutura, como rodovias, ferrovias, empreendimentos hidrelétricos, mineração, entre outros. Um sistema adequado de drenagem e manejo de águas pluviais em áreas urbanas é importante para a população das cidades, uma vez que com a ocupação de áreas cada vez mais extensas, acumulam-se os efeitos negativos decorrentes das precipitações intensas; como alagamentos, inundações, deslizamentos e assoreamento de rios e lagos. Os modelos baseados na revegetação ainda melhoram as características ecológicas e climáticas (MELCHER et al., 2016).

Sistemas de drenagem adequadamente projetados conduzem as águas pluviais com menor perda de solo e/ou cobertura vegetal, controlando a erosão superficial. Tradicionalmente os sistemas de drenagem são projetados com técnicas construtivas da engenharia convencional, como por exemplo, canaletas ou manilhas em concreto, pedra argamassada, tubos perfurados, geossintéticos, brita, entre outros. No entanto, em certos casos, como áreas menos urbanizadas, podem ser utilizadas técnicas alternativas, menos complexas do ponto de vista construtivo e de menor impacto ambiental, que se traduzem em ganhos econômicos e ecológicos.

A Engenharia Natural consiste em um conjunto de técnicas que combinam materiais construtivos inertes com materiais vivos (plantas), e que podem ser utilizadas para estabilização geotécnica, estabilização hidráulica e controle de erosão superficial (SOUSA; SUTILI, 2017). As plantas utilizadas em Engenharia Natural desempenham várias funções técnicas, funcionando, por exemplo, como 
sistemas de ancoragem que estruturam e interligam camadas de solo através de sistemas radiculares (MAFFRA et al., 2017a). As plantas, além de estruturarem o solo têm a capacidade de absorver esforços mecânicos, funcionando como barreira física contra as solicitações do fluxo de água e influenciando a rugosidade hidráulica de canais (SOUSA; SUTILI, 2017). O aumento da rugosidade hidráulica, proporcionado pela presença de plantas tem influência direta na diminuição da velocidade do escoamento, o que consequentemente reduz o potencial erosivo do fluxo de água (HACKER; JOHANNSEN, 2012).

A utilização de soluções construtivas de Engenharia Natural que utilizam vegetação combinada com pedras pode ser uma solução viável para implementar sistemas de drenagem de menor impacto ambiental sem dispensar o atendimento às solicitações para as quais foram projetadas. O objetivo deste trabalho foi apresentar um estudo de caso sobre a implementação de uma estrutura física constituída por soleiras em pedra combinadas com plantas para correção das condições hidráulicas de um canal de drenagem, desde uma breve caracterização projetual até os resultados obtidos dois anos após a sua execução.

\section{RELATO DE CASO}

O ponto de estudo encontra-se localizado junto ao rio Uruguai no município de Aratiba, RS, na divisa entre os estados do Rio Grande do Sul e Santa Catarina

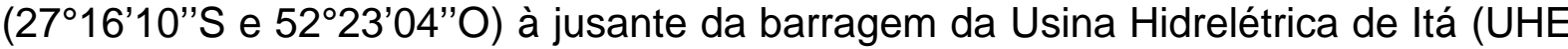
Itá).

A seção de controle da presente intervenção encontra-se no trecho terminal de um canal de drenagem de águas pluviais. A água drenada para o ponto em questão é oriunda de drenagem superficial de parte da encosta esquerda do rio Uruguai e de um trecho de rodovia asfaltada instalada na porção superior da mesma. A pequena bacia de contribuição a montante da seção de controle apresenta relevo ondulado e bastante inclinado com predomínio de vegetação herbácea e arbórea.

O leito do canal junto à seção de controle possui aproximadamente $6,0 \mathrm{~m}$ de largura e taludes de aproximadamente $4,0 \mathrm{~m}$ de altura com pouca ou nenhuma cobertura vegetal. Essa conformação é resultado da alta velocidade do fluxo de água neste ponto, o que provocou erosão do fundo do leito e corrosão das margens esquerda e direita do canal, resultando em taludes potencialmente instáveis. Desta forma detectou-se a necessidade de correção e melhoria das condições hidráulicas e de estabilidade do local, para impedir o avanço da perda de solo e evitar queda de vegetação arbórea nativa instalada no topo de ambos os taludes.

Para tanto, realizou-se primeiramente o dimensionamento hidráulico e hidrológico da bacia de contribuição como pré-requisito ao dimensionamento hidráulico da estrutura física. A determinação da vazão de projeto foi calculada através do método Racional, indicado para bacias de contribuição menores que 2,0 $\mathrm{km}^{2}$. A expressão utilizada para a determinação da vazão de projeto é a seguinte (STEVAUX; LATRUBESSE, 2017):

$$
Q=0,278 \cdot c \cdot i \cdot A
$$

Em que: $Q=$ vazão de projeto $\left(\mathrm{m}^{3} / \mathrm{s}\right) ; c=$ coeficiente de deflúvio (adimensional); $i=$ chuva de projeto $(\mathrm{mm} / \mathrm{h}) ; A=$ área de contribuição $\left(\mathrm{km}^{2}\right)$. 
No cálculo adotou-se um coeficiente de deflúvio igual a 0,6 com base nas características da bacia de contribuição (PINTO et al., 2008). A área da bacia de contribuição é de cinco hectares. A estimativa da intensidade da chuva de projeto para um tempo de retorno de 10 anos foi realizada com base na equação Intensidade-Duração-Frequência (IDF) desenvolvida para o município de Itá - SC para durações de chuva entre cinco minutos e 120 minutos ( $5 \mathrm{~min} \leq \mathrm{t} \leq 120 \mathrm{~min}$ ) (BACK et al.; 2011):

$$
i=\frac{1421,0 \cdot T^{0,1872}}{(t+17,7)^{0,8356}}
$$

Em que: $i=$ chuva de projeto $(\mathrm{mm} / \mathrm{h}) ; T=$ tempo de retorno (anos); $t=$ duração da chuva (min).

O tempo de duração da chuva é o intervalo de tempo contado a partir do início da precipitação para que toda a bacia esteja contribuindo por meio do escoamento superficial na seção de controle ou exutório (tempo de concentração). A seção de controle é o ponto sob intervenção, neste caso, a construção de duas soleiras em pedra. O tempo de concentração foi determinado pela equação de Kirpich publicada no livro Califórnia Culverts Practice, em 1956 (SOUSA et al., 2017):

$$
t c=57 \cdot\left(\frac{L^{3}}{\Delta H}\right)^{0,385}
$$

Em que: $t c=$ tempo de concentração (min); $L=$ comprimento do canal $(\mathrm{km}) ; \Delta h=$ desnível do talvegue $(\mathrm{m})$.

Para as condições da bacia obteve-se um tempo de concentração de aproximadamente 10 minutos para uma chuva de projeto com intensidade de 137 $\mathrm{mm} / \mathrm{h}$. A seguir determinou-se a velocidade de fluxo desenvolvida na seção de controle com base nas condições da bacia. A velocidade de fluxo foi obtida através da equação de Manning (STEVAUX; LATRUBESSE, 2017):

$$
v=\frac{1}{n} \cdot I^{\frac{1}{2}} \cdot R_{h}^{\frac{2}{3}}
$$

Em que: $Q=$ vazão de projeto $\left(\mathrm{m}^{3} / \mathrm{s}\right) ; v=$ velocidade de fluxo $(\mathrm{m} / \mathrm{s}) ; A_{m}=$ área molhada $\left(\mathrm{m}^{2}\right) ; n=$ coeficiente de rugosidade de Manning $\left(\mathrm{s} . \mathrm{m}^{1 / 3}\right) ; I=$ inclinação do canal $(\mathrm{m} / \mathrm{m}) ; R_{h}=$ raio hidráulico $(\mathrm{m})$.

Obteve-se uma velocidade de fluxo em torno de $3,0 \mathrm{~m} / \mathrm{s}$, valor considerado muito alto com base nas características do canal, uma vez que para o material do local (terreno argiloso duro) a velocidade média recomendada é de 1,14 a 1,22 m/s (PORTO, 2006). Uma vez que não se pode alterar a inclinação do curso de água a montante da seção de controle, devido à presença de vegetação arbórea, foi necessária dimensionar uma técnica que resistisse à alta velocidade da água, 
corrigindo as condições hidráulicas do local, diminuindo riscos de erosão de fundo do leito e de suas margens.

Optou-se por uma solução técnica de revestimento do canal com pedra e execução de duas soleiras em pedra, por forma a aumentar a rugosidade hidráulica e dissipar a velocidade da água, impedindo a erosão do leito e das margens, assim como das áreas a jusante da intervenção. Esta solução construtiva foi adotada com sucesso para canais com condições semelhantes em uma intervenção realizada no Espírito Santo (SOUSA et al., 2017).

Com base nesta premissa, a partir da velocidade do fluxo na seção de controle foram dimensionados os blocos de pedra, de tal modo que os mesmos apresentassem velocidade limite de transporte superior à competência do canal. $A$ velocidade limite de transporte pode ser definida como a velocidade necessária para colocar materiais em movimento ou, então, para mantê-los em movimento (DURLO; SUTILI, 2014). A dimensão dos blocos foi estimada a partir da seguinte equação:

$$
b=\frac{v^{2} \cdot \mu \cdot \gamma}{2 \cdot g \cdot f\left(\gamma_{1}-\gamma\right) \cdot \cos \alpha}
$$

Em que: $b=$ dimensão dos blocos (m); $v=$ velocidade do fluxo (m/s); $\mu=$ fator de forma; $g=$ aceleração da gravidade $\left(\mathrm{m} / \mathrm{s}^{2}\right) ; f=$ coeficiente de atrito entre o sólido e 0 leito; $\gamma_{1}=$ peso específico da rocha $\left(\mathrm{kN} / \mathrm{m}^{3}\right) ; \gamma=$ peso específico da água $\left(\mathrm{kN} / \mathrm{m}^{3}\right) ; \alpha$ = ângulo de inclinação do leito.

Após aplicação das equações acima, obteve-se uma vazão de projeto de 1,14 $\mathrm{m}^{3} / \mathrm{s}$ com velocidade de fluxo capaz de transportar pedras com diâmetro de até 0,64 m. Por questão de segurança, optou-se por usar pedras com tamanho mínimo de $0,70 \mathrm{~m}$ para execução das soleiras. Com base no dimensionamento do material construtivo da estrutura deu-se início à execução.

A técnica projetada para a solução dos problemas erosivos do local consistiu na execução de duas soleiras em pedra dispostas transversalmente ao sentido de fluxo dentro do canal. Desta forma pretendeu-se impedir a continuidade de escavação do fundo do leito e criar dois perfis de compensação para diminuir a velocidade da água drenada da encosta, proporcionando condições favoráveis à deposição de sedimentos carreados de montante. Além disso, executou-se um enrocamento ao longo da margem direita e esquerda do canal, de modo a impedir a continuidade da corrosão da base de ambos os taludes. Foi também previsto o plantio de espécies arbustivas reófitas no leito e nas margens que contribuem para o aumento da rugosidade hidráulica aumentando a deposição de sedimentos no enrocamento.

Para tanto foi utilizada uma retroescavadeira para a movimentação e disposição final das pedras dentro do canal. As pedras foram obtidas nas proximidades da obra, junto à margem esquerda do rio Uruguai. Durante a construção, cada pedra foi disposta individualmente, prestando-se especial atenção para que ficassem perfeitamente encaixadas, resultando em uma estrutura única e resistente. Este aspecto foi especialmente observado na construção do enrocamento longitudinal para proteção da base do talude esquerdo e direito do canal.

A execução da estrutura foi realizada em fevereiro de 2017, sendo necessárias aproximadamente 16 horas de máquina. As dimensões da estrutura 
após intervenção são aproximadamente 6,0 m de largura e 20,0 m de comprimento. $O$ volume total de pedras utilizadas foi de aproximadamente $20,0 \mathrm{~m}^{3}$. O aspecto geral da obra durante e logo após a execução pode ser observado na FIGURA 1.

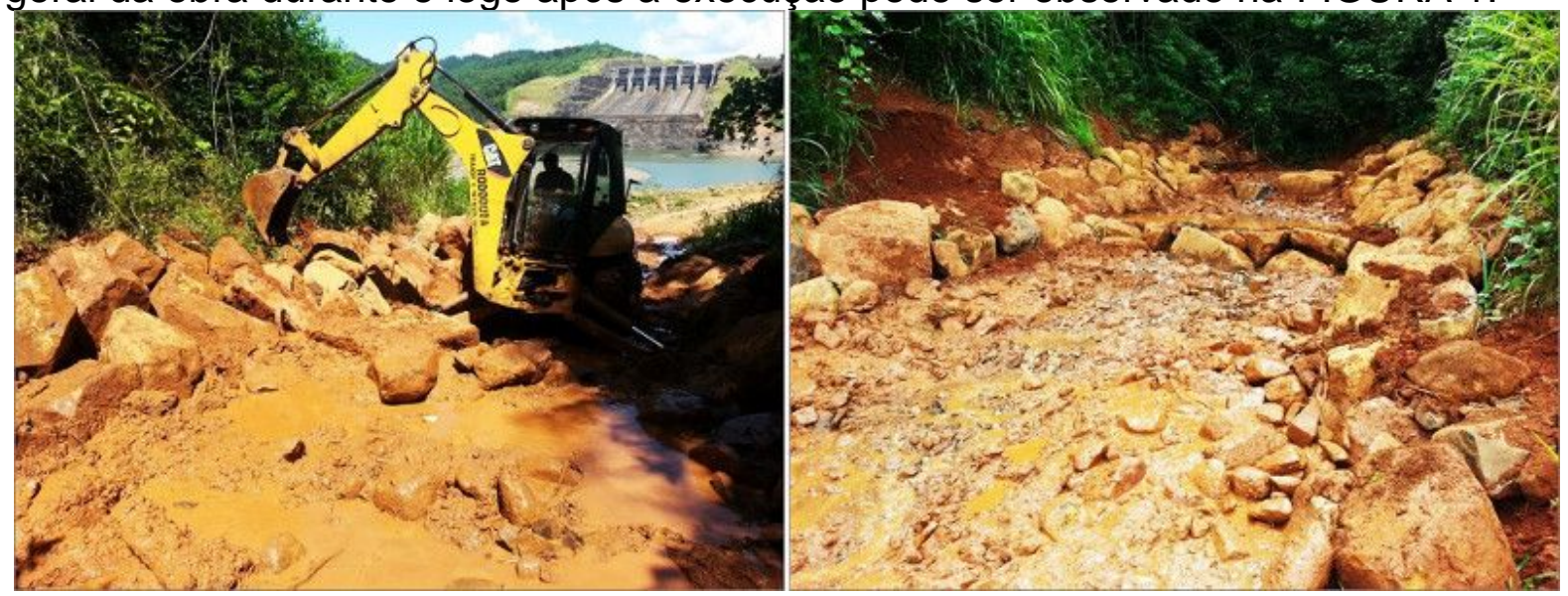

FIGURA 1 - Execução das soleiras e proteção da base do talude da margem esquerda e margem direita em fevereiro de 2016 (à esquerda). Aspecto geral da área logo após a execução da estrutura em fevereiro de 2016 (à direita). Fonte: Junior J. Dewes (acervo pessoal).

Imediatamente após a execução da estrutura em pedra realizou-se o plantio de mudas e estacas vivas de espécies reófitas autóctones no leito do canal de drenagem e no enrocamento nas margens. As espécies foram plantadas em uma densidade de 4 un. $/ \mathrm{m}^{2}$, totalizando 560 plantas em uma área aproximada de $140 \mathrm{~m}^{2}$.

No plantio foram utilizadas mudas de no mínimo $0,50 \mathrm{~m}$ de altura produzidas previamente no Horto Botânico da UHE Itá. O plantio das mudas, quando necessário, foi realizado mediante aplicação de $400 \mathrm{~mL}$ de hidrogel e adubo químico e orgânico previamente incorporado ao solo dentro da cova. As espécies plantadas por meio de mudas foram Ludwigia elegans (Cambess.) H. Hara, Piper aduncum L. e Cephallanthus glabratus (Spreng.) K. Schum.

As estacas vivas das espécies propagadas diretamente no local de forma vegetativa apresentaram comprimento de $0,50 \mathrm{~m}$ e diâmetros variando entre $1,5 \mathrm{~cm}$ e 2,5 cm. As estacas foram inseridas até $0,40 \mathrm{~m}$ de seu comprimento dentro do solo, de modo a evitar o ressecamento do lenho e possibilitar a brotação posterior. As espécies plantadas por meio de estacas vivas foram Phyllanthus sellowianus (Klotzsch) Müll. Arg., Terminalia australis Cambess. e Gymnanthes schottiana Müll. Arg.. A FIGURA 2 apresenta as atividades de revegetação e o aspecto geral da área logo após o plantio das espécies reófitas. 


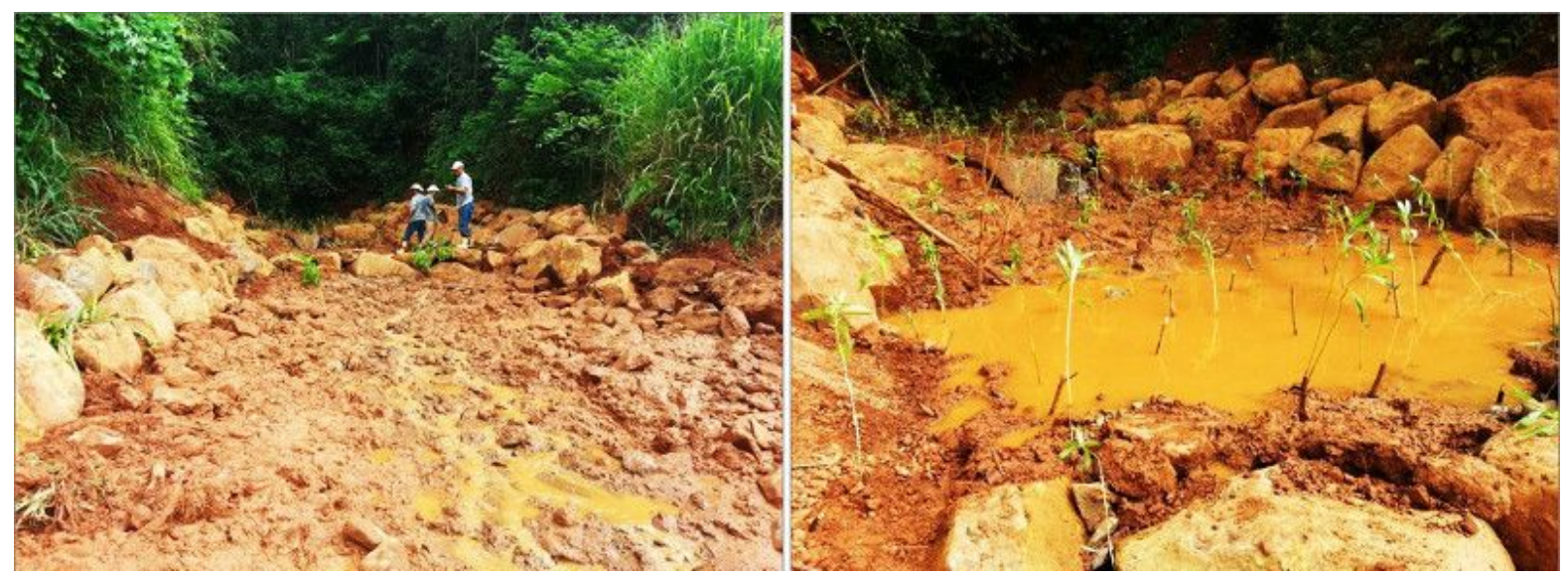

FIGURA 2 - Início do plantio de estacas vivas e mudas no leito e nos taludes da margem direita e margem esquerda em fevereiro de 2016 (à esquerda). Aspecto geral da área logo após o término do plantio de estacas vivas e mudas em fevereiro de 2016 (à direita). Fonte: Junior J. Dewes (acervo pessoal).

As atividades de plantio considerando o transporte de mudas, coleta de estacas vivas e plantio propriamente dito foram executadas em oito horas de trabalho com o auxílio de seis colaboradores. A área foi avaliada qualitativamente em relação ao desenvolvimento das plantas e estabilidade da obra. Foram realizadas três avaliações a campo: no momento da execução, 12 meses e 24 meses após a execução da obra.

\section{RESULTADOS E DISCUSSÃo}

Os resultados observados para dois anos após a execução da obra mostram efeitos técnicos, hidráulicos e ecológicos positivos. A FIGURA 3 apresenta os dados pluviométricos registrados pela estação pluviométrica instalada próximo à barragem da usina hidrelétrica de Itá (UHE Itá) e as temperaturas médias mensais. Os dados de precipitação e temperatura correspondem a dois anos de acompanhamento, desde o término da execução da obra, em fevereiro de 2016, até janeiro de 2018.

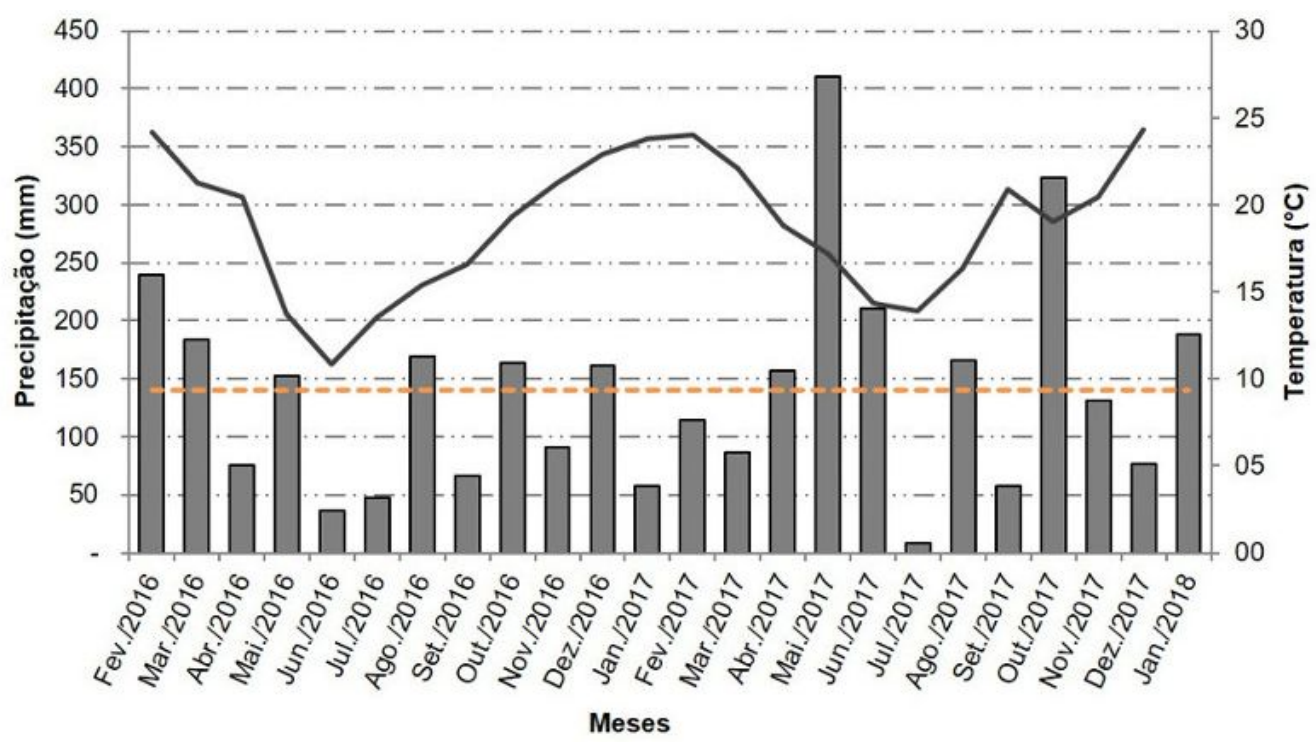

FIGURA 3 - Precipitação acumulada temperaturas médias mensais para o local de execução das soleiras em pedra desde o mês de fevereiro de 2016 (logo após a execução) até janeiro de 2018 (dois anos após a execução). A linha laranja representa a precipitação média mensal para os 2 anos.

ENCICLOPÉDIA BIOSFERA, Centro Científico Conhecer - Goiânia, v.15 n.27; p. 535 
Pode-se observar que a média de precipitação mensal para os dois anos analisados foi de $141 \mathrm{~mm}$, sendo que maiores precipitações acumuladas foram registradas para o ano de 2017 (1798 mm) em comparação com o ano anterior (1471 mm). A maior precipitação diária após a execução da obra para o ano de 2016 foi registrada em 22/03/2016 (60 mm) (início do outono). No ano de 2017 a maior precipitação diária foi verificada no dia 05/06/2017 (100 mm) (final do outono). Apesar da grande quantidade de precipitação diária registrada em junho de 2017, nenhum dano estrutural ou movimentação de pedras foi verificado no local, o que confirma, em parte, o adequado dimensionamento das pedras utilizadas na construção das soleiras.

A partir da FIGURA 4 também se pode observar a manutenção da vitalidade e a recuperação ambiental do local. A ocorrência regular de chuvas, principalmente nos primeiros meses após a execução da obra, contribuiu para a manutenção da viabilidade e o bom desenvolvimento das estacas vivas e mudas das espécies implantadas.
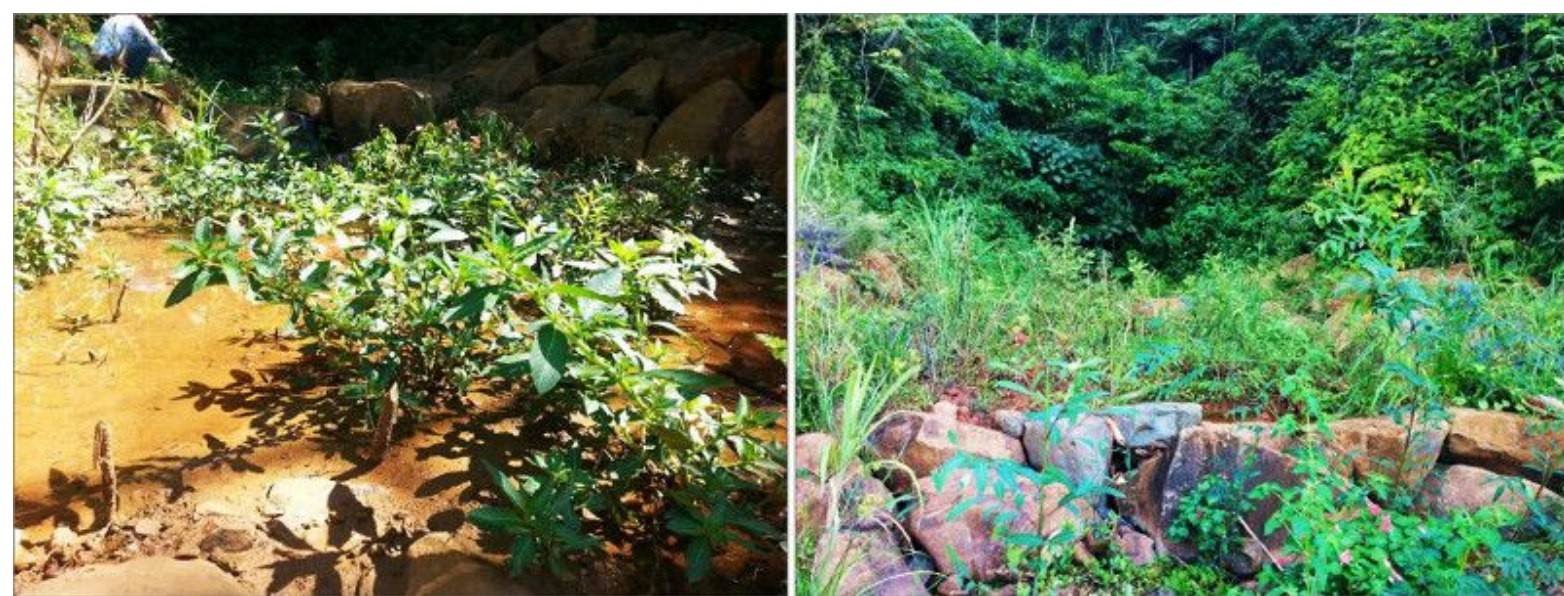

FIGURA 4 - Detalhe das soleiras com desenvolvimento das plantas no leito do canal em setembro de 2016 (à esquerda). Aspecto geral das soleiras com desenvolvimento das plantas no leito do canal e nos taludes em fevereiro de 2017 (à direita). Fonte: Junior J. Dewes e Rita S. Sousa (acervo pessoal).

O uso de plantas no leito do canal mostrou-se importante no aumento da rugosidade hidráulica e diminuição da velocidade da água na seção de controle. $\mathrm{Na}$ FIGURA 4 (à esquerda) pode-se observar a deposição de sedimentos oriundos de montante, o que atesta a redução na velocidade do fluxo de água no local, resultante da execução dos dois perfis de compensação e pela parte aérea das plantas. $O$ uso de espécies com capacidade de sobrevivência em ambientes constantemente alagados e com características morfológicas adequadas da parte aérea, como emissão de grande número de brotos com diâmetros reduzidos e com alta flexibilidade contribuiu, em grande parte, para uma mudança positiva nas condições hidráulicas do canal ao longo de todo o trecho tratado. Concordando com as informações de diversos autores (WEISSTEINER et al. 2016; MELCHER et al. 2016).

Ainda na FIGURA 4 (à direita) pode-se observar também a presença de vegetação em desenvolvimento no enrocamento executado nos taludes da margem direita e esquerda. As espécies implantadas entre as pedras nos taludes, 
nomeadamente Piper aduncum e Gymnanthes schottiana apresentaram taxas de sobrevivência satisfatórias, no entanto, as taxas de desenvolvimento destas plantas permaneceram abaixo do esperado, resultado do efeito de sombreamento causado pelas árvores do remanescente florestal localizado nas adjacências da obra. Devido a este fator houve uma limitação da exposição das plantas à radiação solar, sendo este efeito mais acentuado no inverno, retardando o crescimento na fase inicial.

$\mathrm{Na}$ fase inicial, as espécies Ludwigia elegans e Phyllanthus sellowianus implantadas no leito do canal, apresentaram um ótimo desenvolvimento vegetativo (FIGURA 4). Isto se deve ao fato de que estas espécies estão estritamente ligadas à ambientes úmidos (reofilia), como nas margens junto à linha de água ou inclusive no centro do canal fluvial.

Outro aspecto importante do ponto de vista ecológico observado no local foi a colonização espontânea da área por algumas espécies vegetais herbáceas e semilenhosas autóctones, conforme pode ser observado na FIGURA 5. Estas espécies já ocorriam em alguns pontos ao longo da margem esquerda do rio Uruguai próximo ao local da obra, principalmente em pontos de insurgência ou drenagem de água. As espécies colonizadoras observadas foram Ludwigia longifolia (DC.) H. Hara, Impatiens walleriana Hook. f. e Commelina diffusa Burm.. A presença destas espécies supõe as boas condições criadas, principalmente hidráulicas e ecológicas, por meio da execução das soleiras em pedra, proporcionando meios favoráveis à colonização espontânea.
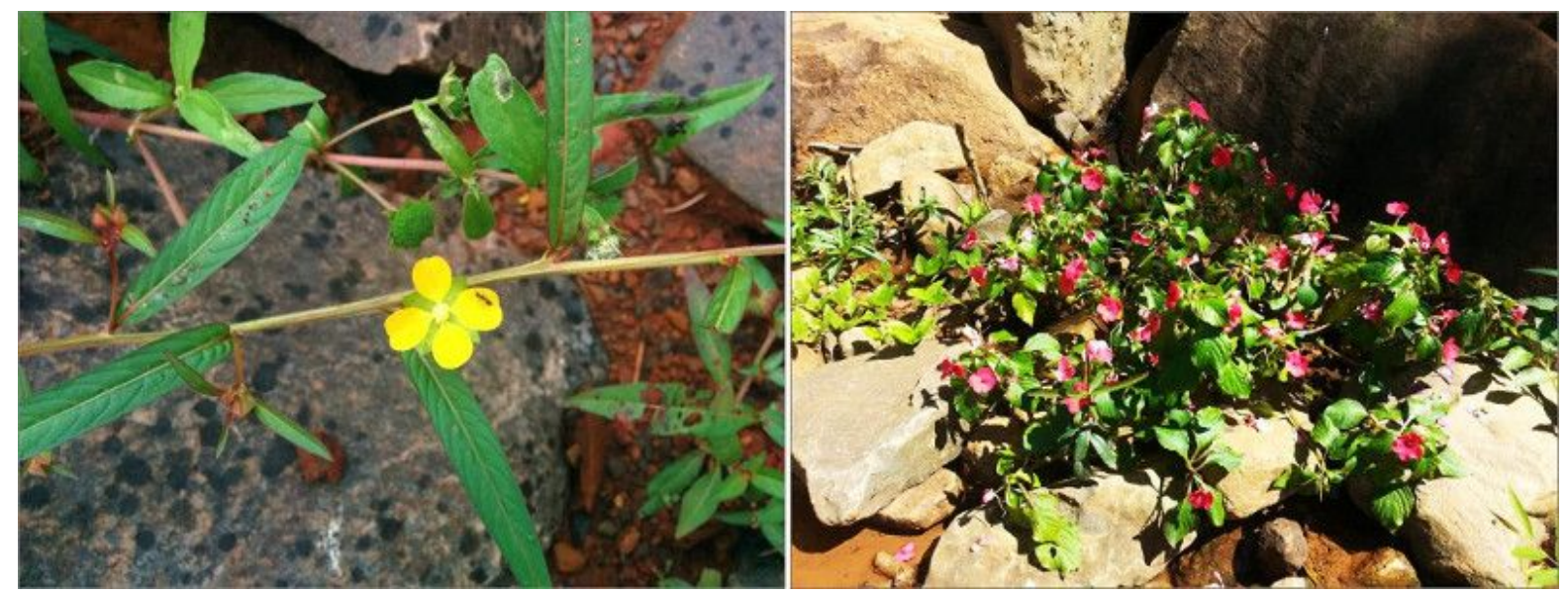

FIGURA 5 - Colonização espontânea pela espécie Ludwigia longifolia junto à margem enrocada em março de 2016 (à esquerda). Colonização espontânea pela espécie Impatiens walleriana no leito do canal em setembro de 2016 (à direita). Fonte: Rita S. Sousa e Junior J. Dewes (acervo pessoal).

Após dois anos de acompanhamento qualitativo da obra é possível afirmar que a técnica executada permanece estável e cumprindo com os objetivos técnicos para a qual foi projetada. Não foi verificada nenhuma instabilidade nos taludes da margem direita e esquerda do canal, encontrando-se atualmente densamente revegetados e com boa cobertura superficial (FIGURA 6). 


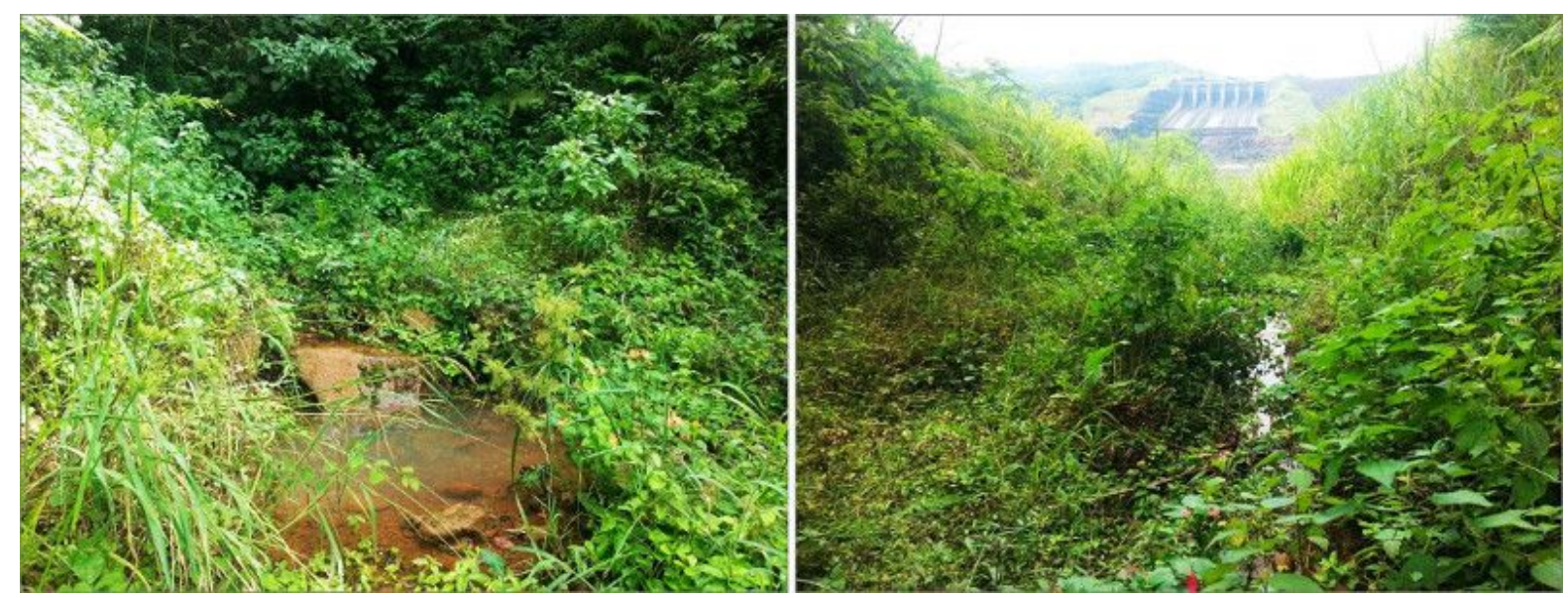

FIGURA 6 - Aspecto geral da área 24 meses após a execução. Vista para montante (à esquerda) e vista para jusante (à direita). Fonte: Junior J. Dewes (acervo pessoal).

Em ambas as margens foram constatadas a presença das espécies Piper aduncum e Leandra regnellii (Triana) Cogn., que são plantas típicas do estrato inferior da Mata Atlântica e adaptadas a ambientes com restrições de luminosidade. Pode-se observar também em menor densidade a presença das espécies Gymnanthes schottiana, Phyllanthus sellowianus, Cephallanthus glabratus, Terminalia australis, Ludwigia elegans e Impatiens walleriana, o que confirma suas aptidões técnicas para uso combinado com soleiras em pedra. Além disso, observou-se a entrada espontânea de várias outras espécies vegetais, principalmente gramíneas, a partir de um ano depois da execução (FIGURA 6).

Os efeitos benéficos, tanto hidráulicos quanto ecológicos, observados pelo emprego de plantas para este tipo de intervenção corroboram com os resultados encontrados em outras intervenções de estabilização hidráulica realizadas com técnicas de Engenharia Natural (KETTENHUBER et al., 2017; MAFFRA, et al., 2017b; SOUSA et al., 2017).

A proteção das bases de ambos os taludes com pedras também continua a mostrar-se eficiente aos 24 meses após execução, de modo que os processos erosivos anteriormente atuantes foram completamente controlados, impedindo novas perdas de solo e prováveis quedas de árvores nativas remanescentes da Mata Atlântica localizada na crista dos taludes. De modo geral, a estrutura foi capaz de diminuir com eficiência a velocidade do fluxo e promover a deposição de sedimentos tanto no leito como nas margens, melhorando substancialmente as condições hidráulicas do local (NEPF; GHISALBERTI, 2008). Também não foi observada a ocorrência de processos erosivos a jusante da área de intervenção.

\section{CONCLUSÃO}

A partir dos resultados qualitativos observados para o presente estudo conclui-se que:

A instalação de soleiras em pedra transversais ao fluxo e a proteção da base dos taludes com enrocamento estagnou a erosão do fundo do leito e das margens do canal de drenagem; 
A intervenção mostrou-se eficiente na melhoria das condições hidráulicas do local, especificamente na diminuição da velocidade da água e na deposição de sedimentos no fundo do leito e nas margens oriundos de montante;

A estrutura proporcionou condições hidráulicas e ecológicas favoráveis ao desenvolvimento vegetativo das mudas e estacas vivas das espécies implantadas e à entrada espontânea de novas espécies no local;

A intervenção permitiu o controle dos processos erosivos atuantes e a recuperação ambiental da área alterada, resultando em ganhos ambientais, ecológicos e estéticos.

\section{REFERÊNCIAS}

BACK, A. J.; HENN, A.; OLIVEIRA, J. L. R. Heavy rainfall equations for Santa Catarina, Brazil. Revista Brasileira de Ciência do Solo, v. 35, n. 6, p. 2127-2134, 2011. Disponível em: <https://doi.org/10.1590/S0100-06832011000600027>. DOI: 10.1590/S0100-06832011000600027.

DURLO, M.; SUTILI, F. Bioengenharia - Manejo biotécnico de cursos de água. 3a ed. Santa Maria: Pallotti, 2014.

HACKER, E.; JOHANNSEN, R. Ingenieurbiologie. Verlag Eugen Ulmer, Stuttgart. 2012.

KETTENHUBER, P. L. W.; DEWES, J. J.; SUTILI, F. J. Engenharia Natural para estabilização hidráulica do Rio Pardinho em Santa Cruz do Sul - RS. Ciência \& Ambiente, v. 46/47, p. 111-130, 2017. Disponível em:

<http://w3.ufsm.br/cienciaeambiente/resenha.php?IDResenha=535>.

MAFFRA, C. R. B.; MORAES, M. T.; SOUSA, R. S.; SUTILI, F. J.; PINHEIRO, R. J. B.; SOARES, J. M. D. Métodos de avaliação da influência e contribuição das plantas sobre a estabilidade de taludes. Scientia Agraria, v. 18, n. 4, p. 129-143, 2017a. Disponível em: <http://dx.doi.org/10.5380/rsa.v18i4.52543>. DOI:

10.5380/rsa.v18i4.52543.

MAFFRA, C. R. B.; SOUSA, R. S.; SUTILI, F. J. Engenharia Natural para estabilização de travessia dutoviária - Caso 2. Ciência \& Ambiente, v. 46/47, p. 153-176, 2017b. Disponível em:

<http://w3.ufsm.br/cienciaeambiente/resenha.php?IDResenha=537>.

MELCHER, A.; DOSSI, F.; GRAF, W.; PletTERBAUER, F.; SCHAUFLER, K.; KALNY, G.; et al., Der Einfluss der Ufervegetation auf die Wassertemperatur unter gewässertypspezifischer Berücksichtigung von Fischen und benthischen Evertebraten am Beispiel von Lafnitz und Pinka. Österreichisches Wasser und Abfallwirtschafts Journal, 68, 308-323. 2016.

NEPF, H., GHISALBERTI, M. Flow and transport in channels with submerged vegetation. Acta Geophys. 56 (3), 753-777, 2008.

PINTO, N. L. S.; HOLTZ, A. C. T.; MARTINS, J. A.; GOMIDE, F. L. S. Hidrologia básica. 11a ed. São Paulo: Edgard Blucher Ltda., 2008. 
PORTO, R. Hidráulica básica. 4a ed. São Carlos: Escola de Engenharia de São Carlos, USP, 2006.

SOUSA, R. S.; MAFFRA, C. R. B.; SUTILI, F. J. Engenharia Natural para estabilização de travessia dutoviária - Caso 1. Ciência \& Ambiente, v. 46/47, p. 131-152, 2017. Disponível em:

<http://w3.ufsm.br/cienciaeambiente/resenha.php?|DResenha=536>.

SOUSA, R. S.; SUTILI, F. J. Aspectos Técnicos das Plantas utilizadas em Engenharia Natural. Ciência \& Ambiente, v. 46/47, p. 31-71, 2017. Disponível em: $<$ http://w3.ufsm.br/cienciaeambiente/resenha.php?|DResenha=532>.

STEVAUX, J. C.; LATRUBESSE, E. M. Geomorfologia fluvial. São Paulo: Oficina de Textos, 2017.

WEISSTEINER, C.; JALONEN, J.; JARVELA, J.; RAUCH, H.P. Spatial-structural properties of woody riparian vegetation with a view on reconfiguration under hydrodynamic loading (vol 85, pg 85, 2015) ECOL ENG. 2016. 